\title{
Acoustic Shielding of Nano-Particle Reinforced Composites
}

\author{
Asim Sneh*, Manshu Gupta*, \\ Akansh Vishwakarma*, Anuj Gupta* \\ *B. Tech Mechanical Engineer, SMEC, \\ Vellore Institute of Technology Chennai, \\ Tamil Nadu - 600127
}

\author{
Lakshmi Ramya Marineni** \\ ${ }^{* *}$ B. Tech Electronics And Communication Engineer, \\ SENSE,Vellore Institute of Technology Chennai, \\ Tamil Nadu - 600127
}

\begin{abstract}
Sustainable flexible foam reinforced with different mixtures of Multiwall Carbon Nanotubes (MWCNT), Copper Oxide $(\mathrm{CuO})$ and Bamboo Charcoal nanoparticles has been prepared using a general mixing process. The sound damping capacity of in total five reinforced samples and an unreinforced sample has been found using sound absorption measurement Setup also called impedance tube setup. The sample A5 performed well in the frequency range of $200-440 \mathrm{~Hz}$. Sample A3 has the best sound damping capacity in the range of 440-680 $\mathrm{Hz}$ and sample $\mathrm{A2}$ did well in the frequency range of 680-1600 Hz. Sample A5 saw a dropdown in the sound absorption in the higher frequency range in comparison to the non-reinforced foam.
\end{abstract}

Keywords- Sustainable flexible foam, Sound damping capacity, Nanoparticles, Impedance tube, frequency

\section{INTRODUCTION}

Sound is the propagation of disturbance in fluid or in solid, principally; a wave motion is set off when an element sets the nearest particle of air into motion, which then creates a difference in pressure in the medium where the wave travels [1]. Though the sound is a very important physical phenomenon in the modern world the unwanted sound also known as noise is a big problem and creates sleep disorders and other health-related issues [3-5]. So, sound absorption becomes a required feature of many material applications [2]. From building material, to protect the living and working spaces from unwanted noise to aerospace material to protect the passenger chamber from loud ear bursting sound of the engine in the case of an airplane and propellant reaction in the case of a rocket, all require very good sound damping capacity. A material can become sound damper by four means. The first is the thickness, with the increase of it the material is more soundproof. The second is wave scattering capability which reduces the energy of the sound wave by scattering it into different directions. The third is the wave trapping capability and the fourth is the capability to stop a vibration to build up and radiate as a sound. Based on the required application, with any of the four or a number of combinations of the above capabilities, good sound-absorbing material can be made. Foams especially flexible foams are considered as very good sound damping materials. The only limitation to them is that they require large thickness to provide good sound absorption capability. So, it becomes important to find out some materials that can overcome this limitation. As always composites can be the solution. The only requirement is to test different composites and investigate that can they be the required material for better sound absorption. We have taken an endeavor to achieve the required goal and are trying the flexible foam with different mixtures of nanoparticles such as MWCNT, $\mathrm{CuO}$ and Bamboo Charcoal as a reinforcement. We are investigating the sound-absorbing capacity of these reinforced samples and making and comparative study of them with that of the normal foam sound damping ability.

\section{METHODOLOGY}

\subsection{Fabrication}

A flexible foam without any reinforcement can be prepared by carrying out an exothermic reaction of synthetic Polyol and isocyanides in the ratio of $2: 3$ by volume [6]. The effervescence of carbon-dioxide is released and the whole process can be carried out in a container with waxed walls for easy removal of the product as shown in figure 1. For the preparation of Nano-particle reinforced foam, the nanoparticles are added directly in the reaction container with the other chemicals of the process stated above. Five nanoparticles reinforced foams have been prepared with mixtures of MWCNT, $\mathrm{CuO}$ and Bamboo Charcoal in different ratios by weight as mentioned in Table 1 .

Table1. Different weight proportions of nanoparticles

\begin{tabular}{|c|c|c|c|}
\hline Specimen & $\begin{array}{c}\text { MWCNT } \\
\text { (wt.\%) }\end{array}$ & $\begin{array}{c}\text { CuO } \\
\text { (wt.\%) }\end{array}$ & $\begin{array}{c}\text { Bamboo Charcoal } \\
\text { (wt.\%) }\end{array}$ \\
\hline A1 & 1.00 & 2.0 & 2.0 \\
\hline A2 & 0.75 & 0.5 & 1.5 \\
\hline A3 & 0.75 & 1.5 & 1.5 \\
\hline A4 & 0.75 & 1.5 & 0.5 \\
\hline A5 & 0.75 & 1.5 & 2.5 \\
\hline
\end{tabular}

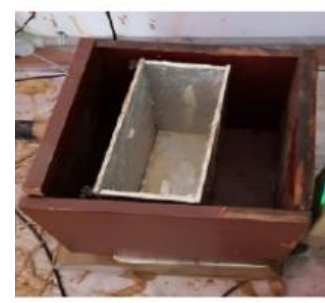

Figure 1. Waxed wall reaction container

\subsection{Sound Absorption Measurement Setup}

A test setup containing an impedance tube of length $900 \mathrm{~mm}$ and internal diameter $56 \mathrm{~mm}$, a speaker with a frequency range of $200 \mathrm{~Hz}-1600 \mathrm{~Hz}$ a pair of microphones, a PC 
automated measurement controller using MATLAB software has been installed. The sample is positioned at one end of the setup with the speaker at the other end and the microphones in the middle. The microphones and the speaker are connected to the controller and MATLAB software is used to calculate the Sound Absorption Coefficient of the sample from the collected data. A simple diagram of the whole setup has been represented in Figure 2.

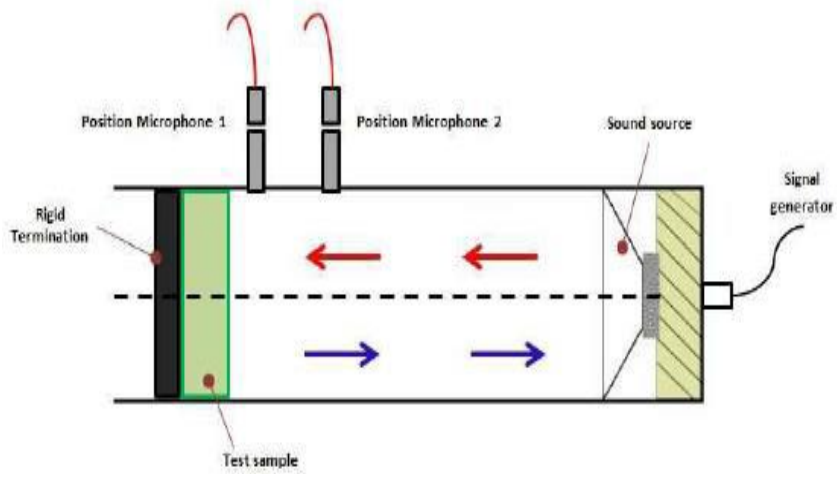

Figure 2. Sound Absorption Measurement Setup

\subsubsection{MATLAB code used}

clc

clear all

lower_frequency_limit $=200$;

higher_frequency_limit $=1600$;

dataset = xlsread('xyz.csv',' A3:C8194');

$\mathrm{t}=$ dataset(:,1); \% Time data

$\mathrm{m} 1=$ dataset $(:, 2) ; \%$ Microphone 1 data

$\mathrm{m} 2=$ dataset $(:, 3) ; \%$ Microphone2 data

$\%$ Transfer Function

period $=60 ; \%$ period of recording

temperature $=28 ; \%$ room temperature

pressure $=101.325 ; \%$ atmospheric pressure, $\mathrm{kPa}$

$\mathrm{f}=6400 ; \%$ sampling rate

$\rho=1.21 ; \%$ density of air, $\mathrm{kg} / \mathrm{m}^{\wedge} 3$

$\mathrm{c}=343 ; \%$ speed of sound, $\mathrm{m} / \mathrm{s}$

$\mathrm{I}=\rho^{*} \mathrm{c} ; \%$ characteristic impedance of air, $\mathrm{kg} / \mathrm{m}^{\wedge} 2 / \mathrm{s}$

$\mathrm{s}=0.077 ; \%$ microphone spacing, $\mathrm{m}$

$\mathrm{x} 1=0.290$;

$\left[\mathrm{H} 12\right.$, frequency] $=$ tfestimate $\left((\mathrm{m} 1),(\mathrm{m} 2),[],[],[], f,{ }^{\prime}\right.$ onesided');

$\mathrm{k}=(2 *$ pi*frequency $) / \mathrm{c}$;

$\mathrm{R}=((\mathrm{H} 12-\exp (-1 \mathrm{i} . * \mathrm{k} . * \mathrm{~s})))$

$\alpha=1$-absI.^2; \%sound absorption coefficient

Is $=\mathrm{I} \cdot *((1+\mathrm{R}) . /(1-\mathrm{R})) ; \%$ surface impedance

Is_n $=((1+\mathrm{R}) . /(1-\mathrm{R})) ; \%$ Normalized surface impedance

$\operatorname{Plot}\left(\right.$ frequency, $\left.\alpha,{ }^{\prime}-{ }^{\prime}\right)$;

\section{RESULTS AND FINDINGS}

\subsection{FTIR Test}

According to the plots obtained from the Fourier Transformation Infrared (FTIR) Spectrum, we have identified the functional groups present in the different foams. The plots obtained are shown below.

- $\quad$ Normal Foam: In the below graph, we can observe the broadening of the peaks in the range near $3500 \mathrm{~cm}^{-1}$ which confirms the presence of $-\mathrm{OH}$ functional group. The stretching of the peaks near the range of $3000 \mathrm{~cm}^{-1}$ confirms the presence of $-\mathrm{C}-\mathrm{H}$ groups. The absorption in the range of $2165-2110 \mathrm{~cm}^{-1}$ shows the presence of cyanide group.

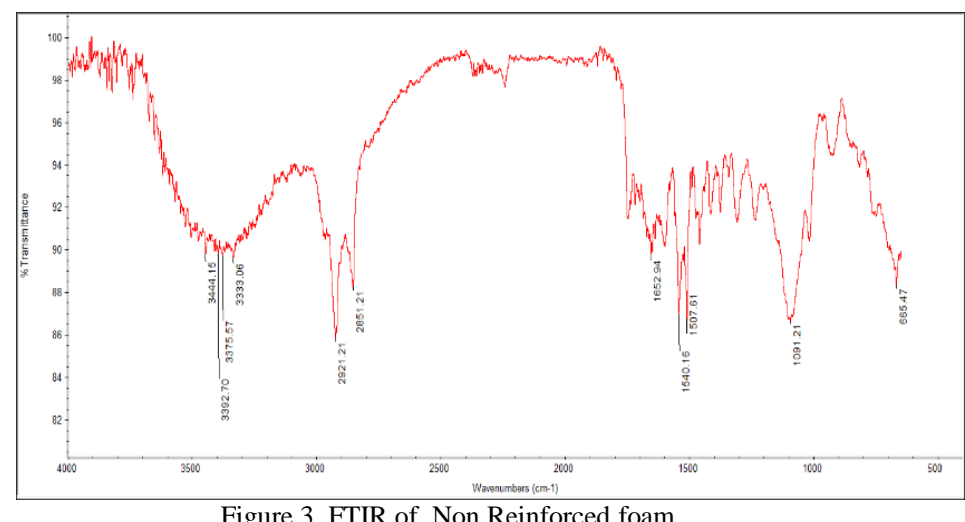

- Reinforced Foam: We can see that figure 4 is different when compared with figure 3. This indicates that some reinforcement has been added to the normal foam. A peak in the range of 1600-1700 $\mathrm{cm}-1$ indicates the presence of SP2 hybridized carbon which is a characteristic of MWCNT due to the presence of carbon-carbon double bond $(\mathrm{C}=\mathrm{C})$. A descent amount of transmittance percentage and deviation from the normal foam FTIR graph indicates that the sample does not has the only MWCNT but also some other reinforcements. The data so collected are not very clean and a lot of noise can be found because of the presence of MWCNT and bamboo charcoal which a mixture of a lot of compounds.

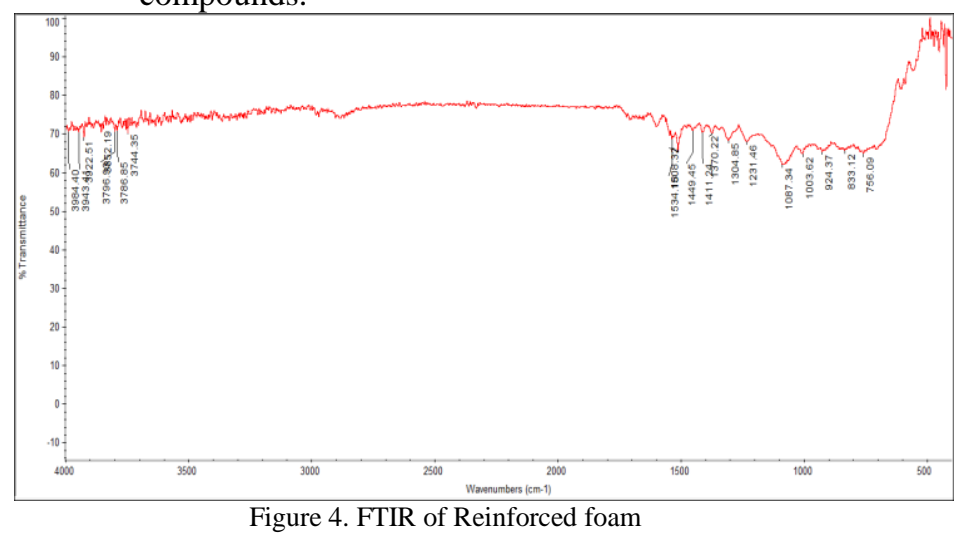

\subsection{Sound Absorption Capability}

Sound absorption capability is characterized by the sound absorption coefficient of the sample, which is calculated using the MATLAB code as mentioned in 2.2.1. The results have been summarized in Table 2 and for a comparative outlook, has also been represented in the form of a graph in figure 3. If we see in the lower frequency range (i.e. 200-440 $\mathrm{Hz}$ ), sample A5 is performing better than any other samples, In the lower-middle frequency range (i.e. 440-680 Hz), sample A3 shows the highest sound absorption and in the higher-middle frequency range (i.e. $680-1100 \mathrm{~Hz}$ ) and in the higher frequency range (i.e. $1100-1600 \mathrm{~Hz}$ ) A2 is the best result showing sample. 


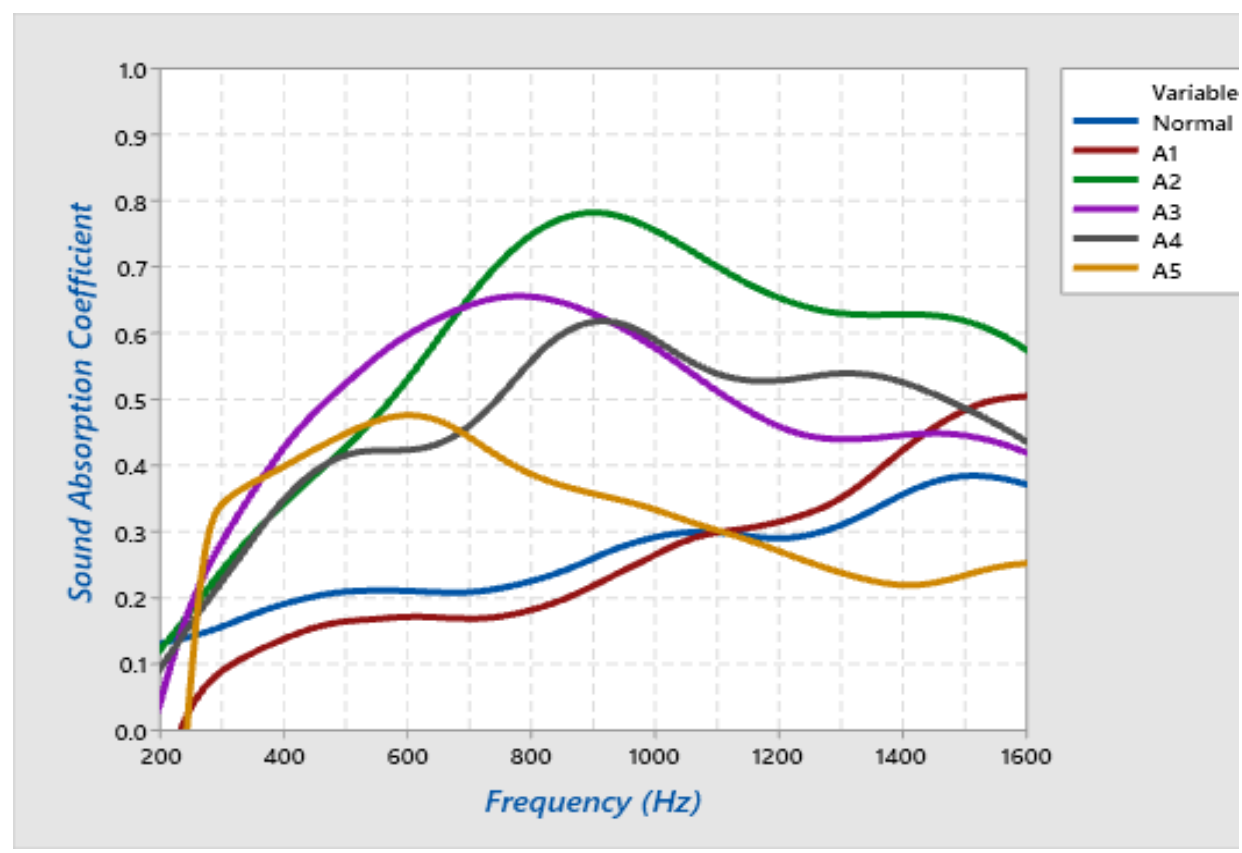

Figure 5. Sound Absorption Coefficient Vs Frequency for different samples prepared

Table 2. Sound Absorption Coefficient of different samples at a frequency range of 200-1600 Hz.

\begin{tabular}{|c|c|c|c|c|c|c|}
\hline \multirow{2}{*}{$\begin{array}{c}\text { Sample } \\
\text { Frequency }\end{array}$} & \multicolumn{6}{|c|}{ Sound Absorption Coefficient } \\
\hline & Normal & A1 & $\mathbf{A 2}$ & $\overline{\mathbf{A 3}}$ & A4 & A5 \\
\hline 200 & 0.138978 & 0.06607 & 0.115342 & 0.169534 & 0.050718 & 0.21081 \\
\hline 256 & 0.05616 & 0.043726 & 0.186852 & 0.118155 & 0.069248 & 0.15802 \\
\hline 320 & 0.20808 & 0.098869 & 0.253094 & 0.345706 & 0.279346 & 0.420389 \\
\hline 352 & 0.198501 & 0.133144 & 0.305122 & 0.407951 & 0.288025 & 0.416755 \\
\hline 400 & 0.209242 & 0.114226 & 0.364487 & 0.435243 & 0.398171 & 0.414222 \\
\hline 440 & 0.18572 & 0.130884 & 0.382006 & 0.470211 & 0.383355 & 0.396926 \\
\hline 560 & 0.205715 & 0.183492 & 0.474183 & 0.559018 & 0.449007 & 0.542663 \\
\hline 600 & 0.240355 & 0.209532 & 0.525623 & 0.594352 & 0.408137 & 0.527393 \\
\hline 680 & 0.218655 & 0.144373 & 0.636581 & 0.666356 & 0.389486 & 0.453416 \\
\hline 730 & 0.150515 & 0.21995 & 0.710428 & 0.655664 & 0.486757 & 0.394403 \\
\hline 800 & 0.187007 & 0.161395 & 0.766682 & 0.654528 & 0.56892 & 0.373135 \\
\hline 900 & 0.256732 & 0.18044 & 0.801372 & 0.642848 & 0.659892 & 0.387319 \\
\hline 1000 & 0.295485 & 0.291116 & 0.766885 & 0.581007 & 0.579474 & 0.321096 \\
\hline 1100 & 0.318448 & 0.355314 & 0.688088 & 0.520552 & 0.491932 & 0.294692 \\
\hline 1200 & 0.272581 & 0.298937 & 0.639919 & 0.414142 & 0.510692 & 0.262151 \\
\hline
\end{tabular}

\section{CONCLUSION}

1. The chemical composition of the samples has been characterized by FTIR test.

2. Many times, the acoustic shielding of nanoparticles reinforced foam has been investigated but a mixture of different nanoparticles reinforced foam has been tried for the first time highlights the novelty of the new work studied.

3. It was found that sample A5 with an average Sound absorption coefficient of 0.32 has better sound absorption ability than other samples in the lower frequency range of 200-440 $\mathrm{Hz}$.

4. A3 with an average sound coefficient of 0.57 showed better sound absorption in the lower-middle frequency of 440-680 Hz.
5. A2 with an average sound absorption coefficient of 0.67 showed the best result in the frequency range of $680-1600 \mathrm{~Hz}$.

6. Except for sample A5, in higher frequency range all the reinforced samples showed better sound absorption than the non-reinforced foam.

\section{REFERENCES}

[1] C. H. Hansen, "Fundamental of Acoustics," University of Adelaide, Adelaide, 2001.

[2] M. N. A. A. Nordin, L. M. Wan , M. H. Zainulabidin , A. S. M Kassim and A. M.Aripin, "Research finding in natural fibers sound absorbing material", ARPN Journal of Engineering and Applied Sciences, ISSN 1819-6608, VOL. 11, NO. 14, JULY 2016.

[3] Hiral J. Jariwala , Huma S. Syed, Minarva J. Pandya , Yogesh M. Gajera, "Noise Pollution \& Human Health: A Review", 
Conference: Noise and Air Pollution: Challenges and Opportunities

[4] Babisch, W. (1998) Epidemiological studies of the cardiovascular effects of occupational noise - a critical appraisal. Noise \& Health 1:24-39

[5] Carter, N.L., Hunyor, S.N., Crawford, G., Kelly, D., Smith, A.J.M. (1994) Environmental noise and sleep - a study of arousals, cardiac arrhythmia and urinary catecholamines. Sleep 17: 298-307

[6] Manshu Gupta, Asim Sneh, Yuvaraj L., Jeyanthi Subramanian, "An Experimental Investigation on the Acoustic and Thermal Properties of Copper Reinforced Sustainable Foam", International Journal of Engineering Research \& Technology (IJERT), Vol. 8 Issue 08, August-2019.

\section{AUTHOR'S PROFILE}

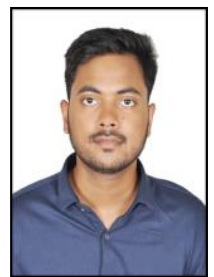

Asim Sneh: B.Tech Mechanical Engineer, School of Mechanical Engineering Chennai (SMEC), Vellore Institute of Technology Chennai. Research areas are Heat Transfer,nanopaticles and nanofluids, EMI and acoustics materials development. Published 3 articles in reputed international journals.

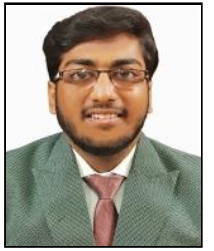

Manshu Gupta: B.Tech Mechanical Engineer, School of Mechanical Engineering Chennai (SMEC), Vellore Institute of Technology Chennai. Research areas are internal combustion engines, nanopaticles, EMI shielding and acoustics materials development. Published 5 articles in reputed international journals.

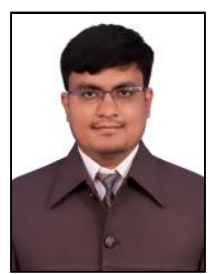

Akansh Vishwakarma: B. Tech Mechanical Engineer, School of Mechanical Engineering Chennai (SMEC), Vellore Institute of Technology Chennai. Research areas are Materials, Thermodynamics, EMI and Automotive Technologies. Published 1 article in reputed international journals.

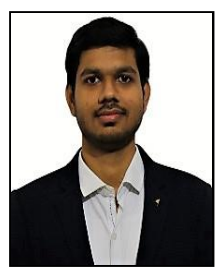

Anuj Gupta: B. Tech Mechanical Engineer, School of Mechanical Engineering Chennai (SMEC), Vellore Institute of Technology Chennai. Research areas are Fabrication and design modelling of student F1 cars, acoustic materials property study. Published 1 article in reputed international journals.

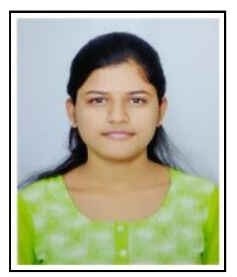

Lakshmi Ramya Marieneni : B. Tech Electronics And Communication Engineer, School of (SENSE), Vellore Institute of Technology Chennai. Research area are VLSI systems, Remote controlled systems, communication devices, wave generation and absorption. 